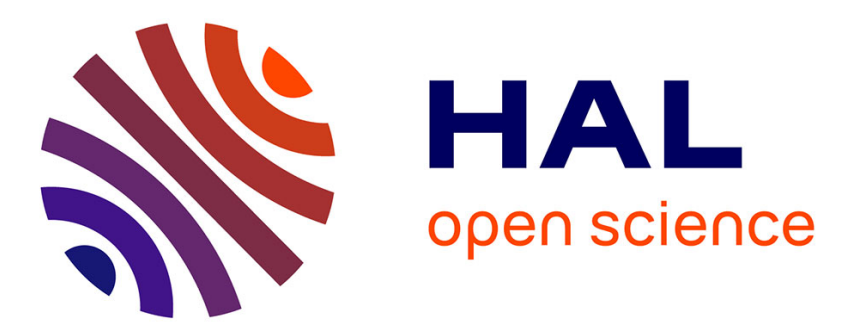

\title{
Utility of Computed Tomography to Predict Ventricular Arrhythmias in Patients With Nonischemic Cardiomyopathy Receiving Cardiac Resynchronization Therapy
}

Vincent Galand, Brian Ghoshhajra, Jackie Szymonifka, Saumya Das, Christophe Leclercq, Raphael P. Martins, Quynh A. Truong, Jagmeet P. Singh

\section{To cite this version:}

Vincent Galand, Brian Ghoshhajra, Jackie Szymonifka, Saumya Das, Christophe Leclercq, et al.. Utility of Computed Tomography to Predict Ventricular Arrhythmias in Patients With Nonischemic Cardiomyopathy Receiving Cardiac Resynchronization Therapy. American Journal of Cardiology, 2020, 125 (4), pp.607-612. 10.1016/j.amjcard.2019.11.003 . hal-02493138

\section{HAL Id: hal-02493138}

\author{
https://hal-univ-rennes1.archives-ouvertes.fr/hal-02493138
}

Submitted on 27 Feb 2020

HAL is a multi-disciplinary open access archive for the deposit and dissemination of scientific research documents, whether they are published or not. The documents may come from teaching and research institutions in France or abroad, or from public or private research centers.
L'archive ouverte pluridisciplinaire HAL, est destinée au dépôt et à la diffusion de documents scientifiques de niveau recherche, publiés ou non, émanant des établissements d'enseignement et de recherche français ou étrangers, des laboratoires publics ou privés. 
Utility of Computed Tomography to Predict Ventricular Arrhythmias in Patients with

Non-ischemic Cardiomyopathy Receiving Cardiac Resynchronization Therapy.

\section{Running title: CT to predict ventricular arrhythmias}

Authors: Vincent Galand MD ${ }^{1,2}$, Brian Ghoshhajra MD ${ }^{3}$, Jackie Szymonifka MA ${ }^{4}$, Saumya Das MD, $\mathrm{PhD}^{2}$, Christophe Leclercq MD, $\mathrm{PhD}^{1}$, Raphaël P Martins, MD, PhD 1, Quynh A. Truong MD, $\mathrm{MPH}^{5}$, Jagmeet P.Singh MD, DPhil ${ }^{2}$

Affiliations : 1 Univ Rennes, CHU Rennes, INSERM, LTSI - UMR 1099, F-35000 Rennes, France ; 2 Cardiology Division, Massachusetts General Hospital, Harvard Medical School, Boston, Massachusetts; 3 Cardiac MR PET CT Program, Department of Radiology (Cardiovascular Imaging), Division of Cardiology, Massachusetts General Hospital, Harvard Medical School, Boston, Massachusetts; 4 Department of Public Health, Division of Biostatistics, New York University, New York; 5 Department of Radiology and Cardiology, Weill Cornell Medicine, New York.

Address for correspondence: Dr. Vincent Galand, Cardiology Division, Massachusetts General Hospital, Harvard Medical School, 55 Fruit Street, Boston, Massachusetts 02114. Email: Vincent.galand35@gmail.com

Funding sources: The study was supported by NIH/NHLBI K23HL098370 and Abbott (formerly St. Jude Medical). Dr. Truong also received support from the NIH L30HL093896. Funders had no role in this study.

Disclosures: Dr Leclercq has received honoraria from Abbott, Medtronic, Boston Scientific, Biotronik, and Livanova. Dr. Truong received grant support from Ziosoft, USA. Singh receives grant support from St. Jude Medical and Boston Scientific and serves as a consultant to LivaNova, St. Jude Medical, Medtronic, Boston Scientific, Impulse Dynamics, Biotronik, EBR Inc, Backebeat Inc. Dr Singh receives research support from Abbott and Boston Scientific. All other authors have no disclosures. 


\section{Abstract}

The residual risk of ventricular arrhythmia (VA) after cardiac resynchronization therapy (CRT) implantation in patients with non-ischemic cardiomyopathy (NICM) remains difficult to evaluate. The impact of left ventricular (LV) wall thickness (WT) measured using computed tomography (CT) on the occurrence of VA after CRT implantation has never been investigated. In this pilot study, we examined the association of LVWT and the occurrence of VA in NICM patients receiving CRT. Thirty three patients with NICM scheduled for CRT underwent pre-procedural CT. Reduced LVWT was defined as WT $<6 \mathrm{~mm}$ and quantified as a percentage of total LV area. The endpoint was the occurrence of VA episode during 2-years follow-up after CRT implantation. During the 2-years follow-up, a total of 37 VA episodes occurred in $6(18.2 \%)$ patients. Patients with VA exhibited significantly higher NT-pro BNP level before CRT implantation. Additionally, CT analysis showed that patients with VA had a higher percentage of total LV with reduced WT compared to those free from VA $(49.5 \% \mathrm{vs}$. $25.8 \%$ respectively, $\mathrm{p}=0.005)$. In multivariable analysis, the total percentage of LV area with WT $<6 \mathrm{~mm}$ was the only predictor of VA (OR: $1.07(1.00-1.14), \mathrm{p}=0.047)$. ROC analysis for total percentage of LVWT $<6 \mathrm{~mm}$ demonstrated that an optimal cut-off value of $40 \%$ differentiated patients at risk of VA. In conclusion, LV WT evaluated using cardiac CT is an independent predictor of VA in NICM patients implanted with CRT. Patients with a total percentage of LV WT $<6 \mathrm{~mm} \geq 40 \%$ are especially at high risk of VA after CRT implantation.

Key words: Cardiac resynchronization therapy; computed tomography; wall thickness; ventricular arrhythmia; non-ischemic cardiomyopathy

\section{Introduction}


Patients with non-ischemic cardiomyopathy (NICM) and reduced left ventricular (LV) ejection fraction (LVEF) are at risk of ventricular arrhythmias (VA) (1-2). However, cardiac resynchronization therapy (CRT) has been shown to reduce the risk of VA, and especially patients with LVEF normalization (3-5). In order to predict the residual risk of VA after CRT implantation, various studies have defined VA predictors (4-6). However, these predictors are difficult to use in clinical practice and the risk of VA remains complex in patients with NICM. Cardiac magnetic resonance (CMR) is able to identify patients at risk of VA (7-8) but this technique is not always available in clinical practice. Computed tomography (CT) seems an ideal noninvasive modality that provides pertinent information to guide the CRT implantation (9). However, the impact of LV wall thickness (WT) measured using CT on the occurrence of VA after CRT implantation has never been investigated. In this pilot study, we aimed to examine the association between LV WT and the occurrence of VA in a prospective cohort of non-ischemic patients receiving CRT.

\section{Methods}

The rationale and design of the Dual-Source Computed Tomography to Improve Prediction of Response to Cardiac Resynchronization Therapy (DIRECT; ClinicalTrial.gov identifier NCT01097733) have been previously published (10). Briefly, 54 refractory heart failure patients with New York Heart Association (NYHA) functional class II-IV, LVEF $\leq 35 \%$ and electrocardiographic QRS duration $>120 \mathrm{~ms}$ were prospectively enrolled for a CRT with defibrillator (CRT-D) implantation procedure (of note, a total of 33 and 21 patients with non-ischemic and ischemic etiology were included, respectively). The CT scan protocol was previously described (10). Before CRT implantation procedure, all patients underwent a 2Dechocardiography performed by the Massachusetts General Hospital Echocardiography Laboratory. The modified biplane Simpson's technique was used to calculate the left 
ventricular end-systolic volume, left ventricular end-diastolic volume, and LVEF. LV diameters were determined following the guidelines of the American Society of Echocardiography. After CRT implantation patients returned for regular clinic visits at 1, 3, and 6 months, and annually thereafter. At each follow-up visit, NYHA Class, global assessment, 6-minute walk distance and 12-lead ECG were assessed. Study clinical follow-up ended at 2 years. In this pilot study, the impact of LV WT on the occurrence of VA was evaluated among the 33 patients with NICM. The study protocol was approved by the institutional review board and all patients provided written informed consent.

All CT images were analyzed using the ADAS-VT software (Galgo Medical, Barcelona, Spain) by an experienced observer, blinded to the clinical data. The performance and the inter- and intra-observatory reproducibility of the software has been previously described (11-12). In this work, using 5 CT images, intra and inter observer variance in assessing the wall thickness measurements was $4 \%$ and $5 \%$. To create the model, CT images were exported in DICOM format and integrated in the software. A total of four landmarks were manually placed (center of the aortic annulus, center of the mitral annulus, LV apex and center of the tricuspid annulus). To adjust the model, the contours of the LV endocardium and epicardium were then manually drawn in $3 \mathrm{LV}$ short axis slices. Then, endocardial and epicardial borders were delimited with a semiautomatic segmentation algorithm. Lastly, a manual adjustment of the LV endocardial and epicardial borders was required to fit the surface to the CT images in the short-axis, two chambers and coronal planes. A 3D visualization of the LV was then created and WT was defined using a color threshold. As previously described, normal LV WT was defined as an end-diastolic WT>6mm and WT $<6 \mathrm{~mm}$ suggested reduced LV WT $(11 ; 13)$. For quantitative analysis, the extent of total WT $<6 \mathrm{~mm}$ burden was quantified as a percentage of total LV area. Additionally, LV was 
automatically segmented in 16 segments and each segment was considered with reduced WT in case of $\mathrm{WT}<6 \mathrm{~mm}$ area location.

The endpoint was the occurrence of VA episode during 2-years follow-up after CRT implantation and was defined as the occurrence of a sustained ventricular tachycardia/fibrillation (VT/VF) treated by an appropriate CRT-D therapy (antitachycardia pacing or shock). Of note, self-limiting VTs were not collected. The number and type of VA and the specific therapy used to restore sinus rhythm were collected.

Qualitative variables are summarized with frequencies (percentage); continuous data as mean \pm standard deviation or median (interquartile range) depending on their distribution, which was assessed using the Kolmogorov-Smirnov test. Categorical variables were compared using the $\chi 2$ tests or Fisher's exact test. Continuous variables were compared using Student's $t$-test or the Mann-Whitney U-test for two-group comparisons. Multivariable analysis and odds ratio (OR) was determined using logistic regression. For the purposes of the multivariable analysis, variables with p-values $<0.05$ in univariate analysis were included. Of note, receiver-operator curves (ROC) were used to categorize LVWT by selecting clinicallyrelevant cut-offs, which were the closest to the optimal cut-off according to the maximum Youden's index (sensitivity + specificity). Survival rates were summarized using KaplanMeier estimates, and log-rank tests were used to compare groups. A p-value $<0.05$ was considered statistically significant. The analyses were performed with the SPSS statistical package, version 11.0 (SPSS Inc., Chicago, IL).

\section{Results}


Among the 54 CRT recipients enrolled in the DIRECT study, a total of $33(61.1 \%)$ patients with NICM were included in this pilot analysis. All patients received a CRT-D at the time of the implantation. After the device procedure, the mean VT and VF detection rates programmed were $183.5 \pm 11.8$ beats/min and $211.5 \pm 15.7$ beats/min, respectively. Of note, the VT zone was activated in only $22(66.7 \%)$ patients and 15 (45.5\%) CRT recipients had an additional VT monitor zone with a VT detection rate of $163.9 \pm 7.0$ beats/min.

During the 2-years follow-up, a total of 37 VA episodes occurred in $6(18.2 \%)$ patients with a median of 3.5 (1.0-4.0) VA episodes per patient. First VA event occurred a mean time of 9.7 \pm 6.3 months after CRT implantation. Among the $37 \mathrm{VA}$ episodes, 36 and 1 were related to VT and VF events respectively. Of note, 9 (24.3\%) VAs required an ICD shock to restore sinus rhythm.

Baseline characteristics between patients with or without VA episode were described in Table 1. Both groups were similar according to the age, body mass index, co-morbidities and baseline medication at the time of the CRT implant. Notably, a total of 4 patients received an anti-arrhythmic drugs at the time of the CRT procedure (1 and 3 patients for a history of atrial or ventricular tachycardia prior to CRT, respectively). Interestingly, patients with VA exhibited significantly higher NT-proBNP level before CRT implantation. There was no difference regarding the echocardiography parameters, although there was a trend in more dilated LV and worst LVEF in patient who experienced at least one VA episode. Conversely, CT analysis showed that patients with VA had significantly larger area with WT<6mm $(118.0$ (72.3-157.2) $\mathrm{cm}^{2}$ vs. $\left.31.8(19.6-66.9) \mathrm{cm}^{2} ; \mathrm{p}=0.018\right)$. Similarly, patients with VA had also a higher percentage of total LV with reduced WT compared to those free from VA $(49.5 \%$ vs. $25.8 \%$ respectively, $\mathrm{p}=0.005)$. Additionally, CRT recipients with VA exhibited a higher number of LV segments with WT<6mm (9.0 (8.0-10.0) vs. 3.5 (2.0-8.0); p=0.016). Interestingly, although that patients with VA had numerically more segments with WT $<6 \mathrm{~mm}$ 
in the basal/mid and apical regions, this difference was only significant in the basal region

(Table 1, Figure 1). Lastly, both groups had similar lead locations and an optimal biventricular pacing rate at 6-months follow-up.

In multivariable analysis, the total percentage of LV area with $\mathrm{WT}<6 \mathrm{~mm}$ was the only predictor of VA after CRT implantation (OR: 1.07 (1.00-1.14), p=0.047). ROC analysis for total percentage of LVWT $<6 \mathrm{~mm}$ demonstrated that an optimal cut-off value of $40 \%$ differentiated patients at risk of VA (sensibility $=71 \%$ and specificity $=78 \%$ ). Indeed, as illustrated in Figure 2, patients with a total percentage of $\mathrm{WT}<6 \mathrm{~mm} \geq 40 \%$ experienced significantly lower VA-free survival probability than those with $<40 \%$. Figure 3 shows an example of patients with $\geq 40 \%$ and $<40 \%$ of total percentage of WT $<6 \mathrm{~mm}$ and with or without VA.

\section{Discussion}

Our study is the first to evaluate the role of CT in quantifying the extent of LV wall thickness in prognosticating the risk of VA after CRT implantation in patients with NICM. The main results of this study are: 1) $18.2 \%$ of the NICM patients presented at least one VA episode in the 2-years follow-up after CRT implantation. 2) The total percentage of LV WT $<6 \mathrm{~mm}$ measured using CT is an independent predictor of the occurrence of VA after CRT implantation. 3) A percentage of total LV with reduced WT $\geq 40 \%$ classified NICM patients at high risk of VA.

In our study, we observed that VA occurred frequently among NICM patients receiving CRT, with a documented rate of $18.2 \%$ of patients after 2-years follow-up. This result is supported by the DAI-PP trial which enrolled up to 5000 patients implanted with an ICD in primary prevention and showed that $21.7 \%$ of the NICM patients experienced at least 
one VA episode during 3-years follow-up (14). Of note, 70\% of the NICM patients included in this registry were implanted with a concomitant CRT. In order to define patients at risk of VA, previous studies have published various VA predictors, mainly based on the response to CRT and the LV reverse remodeling. However few predictors have been developed using the baseline characteristics. In a sub-analysis of the MADIT-CRT study, Ruwald et al. defined 6 baseline factors associated with a decrease risk of VA: female gender, body mass index, LBBB QRS morphology, smoking cessation and the lack of history of VA before CRT implantation. Conversely, Kutyifa et al. found that the LVEF at baseline (i.e. $\leq 30 \%$ of $>30 \%$ ) predicts the risk of VA after CRT implantation in a cohort of ischemic and non-ischemic etiologies (15). In our study, we found no difference regarding the baseline characteristics and echocardiography between patients with or without VA, although there was a trend in more dilated LV and worst LVEF among those who experienced VA event. Despite being helpful to define patients with an expected super-response to CRT, the baseline characteristics and echocardiographic parameters are probably not able to accurately predict the risk of VA after CRT implantation. The use of cardiac imaging modalities which provides precise LV tissue characterization is probably required to define NICM patients at risk of VA.

The analysis of myocardial scar tissue by contrast-enhanced CMR has been correlated to the occurrence of VA among the candidates to CRT. This information is supported by a recent work who investigated the relative benefit of CRT-P or CRT-D according to the absence or presence of LV midwall fibrosis detected by CMR (16). Authors showed that in NICM patients without LV midwall fibrosis, CRT-D implantation was not associated with a better survival compared to CRT-P. Similarly, in a cohort of 217 CRT candidates who underwent contrast-enhanced CMR before device implantation, none of the 92 patients without myocardial scar experienced ICD therapies during follow-up. Additionally, among the 125 patients with late gadolinium enhancement, the total scar mass, core mass, and border 
zone mass were significantly greater in the group with ICD therapies and were predictors of the occurrence of VA, independently of the underlying cardiomyopathy (17). These results suggest that assessment of the myocardial substrate is crucial to identify patients at risk of VA after CRT implantation.

To the best of our knowledge, our study is the first to use CT imaging to predict the occurrence of VA. We showed that WT was an independent predictor of VA after CRT implantation and a percentage of LV with reduced $\mathrm{WT} \geq 40 \%$ correctly classified NICM patients at high risk of VA. Similarly, the relative LV WT has been evaluated among the patients enrolled in the MADIT-CRT study (18). In this work, the relative WT measured at baseline was the best echocardiographic predictor for VA and authors have rightfully suggested that WT may mirror the extent of LV fibrosis and VT substrate. Additionally, in a cohort of $14 \mathrm{HF}$ patients who underwent electro-anatomical mapping, thinner LV was associated with a decrease of local conduction velocity, reduced bipolar/unipolar voltage and larger LV electrograms. These data demonstrated the potential relationship between reduced WT and VT reentrant mechanism (10). We also noted that the location of reduced WT segments (i.e. basal, mid or apical region) may be critical. Indeed, NICM patients with VA exhibited significantly larger area with $\mathrm{WT}<6 \mathrm{~mm}$ in the basal region compared to those without VA. Thinner WT and advanced LV remodeling in the basal segments could possibly promote the occurrence of VA. This hypothesis is supported by recent work who demonstrated that the VT-related substrate was mainly distributed in the basal region in NICM patients who underwent VT ablation (19-20).

These results bring important information and could be helpful in daily clinical practice. First, in contrast with CMR, CT can be much more easily and quickly realized in patient previously implanted with a device (pacemaker or implantable cardioverter defibrillator) and who required and an up-grade to CRT. Second, WT measured using CT 
could potentially identify NICM patients at high risk of VA and consequently guide concomitant ICD indication in NICM candidates to CRT.

The limited sample size makes our pilot study hypotheses generating, and will require validation in larger studies. The relationship between wall thickness and fibrosis is difficult to define and will require evaluation through studies using multi-modality imaging (i.e. CMR and CT). Lastly, depending of the ICD programming, the rate of VA events could be underestimating, especially in patients with only VF activated zone.

\section{Conclusion}

LV WT evaluated using cardiac CT is an independent predictor of VA in NICM patients implanted with CRT. Patients with a total percentage of LV WT $<6 \mathrm{~mm} \geq 40 \%$ are especially at high risk of VA after CRT implantation. This needs to be further validated in a larger cohort of NICM patients receiving CRT.

Acknowledgements: This research was supported by the French Federation of Cardiology and the Rennes University Hospital 


\section{References}

1- Khand A, Gemmel I, Clark AL, Cleland JG. Is the prognosis of heart failure improving? J Am Coll Cardiol 2000;36:2284-2886.

2- Kreuz J1, Horlbeck F, Linhart M, Mellert F, Fimmers R, Schrickel J, Nickenig G, Schwab JO. Independent predictors of mortality in patients with advanced heart failure treated by cardiac resynchronization therapy. Europace 2012;14:1596-1601.

3- Chatterjee NA, Roka A, Lubitz SA, Gold MR, Daubert C, Linde C, Steffel J, Singh JP, Mela T. Reduced appropriate implantable cardioverter-defibrillator therapy after cardiac resynchronization therapy-induced left ventricular function recovery: a metaanalysis and systematic review. Eur Heart J 2015;36(41):2780-2789.

4- Barsheshet A, Wang PJ, Moss AJ, Solomon SD, Al-Ahmad A, McNitt S, Foster E, Huang DT, Klein HU, Zareba W, Eldar M, Goldenberg I. Reverse remodeling and the risk of ventricular tachyarrhythmias in the MADIT-CRT (Multicenter Automatic Defibrillator Implantation Trial-Cardiac Resynchronization Therapy). J Am Coll Cardiol 2011;57(24):2416-2423

5- Killu AM, Mazo A, Grupper A, Madhavan M, Webster T, Brooke KL, Hodge DO, Asirvatham SJ, Friedman PA, Glikson M, Cha YM. Super-response to cardiac resynchronization therapy reduces appropriate implantable cardioverter defibrillator therapy. Europace (2018) 20, 1303-1311

6- Ruwald MH, Solomon SD, Foster E, Kutyifa V, Ruwald AC, Sherazi S, McNitt S, Jons C, Moss AJ, Zareba W. Left ventricular ejection fraction normalization in cardiac resynchronization therapy and risk of ventricular arrhythmias and clinical outcomes: results from the Multicenter Automatic Defibrillator Implantation Trial With Cardiac Resynchronization Therapy (MADIT-CRT) trial. Circulation 2014;130(25):22782286 
7- Acosta J, Fernández-Armenta J, Borràs R, Anguera I, Bisbal F, Martí-Almor J, Tolosana JM, Penela D, Andreu D, Soto-Iglesias D, Evertz R, Matiello M, Alonso C, Villuendas R, de Caralt TM, Perea RJ, Ortiz JT, Bosch X, Serra L, Planes X, Greiser A, Ekinci O, Lasalvia L, Mont L, Berruezo A. Scar Characterization to Predict Life-Threatening Arrhythmic Events and Sudden Cardiac Death in Patients With Cardiac Resynchronization Therapy: The GAUDI-CRT Study. JACC Cardiovasc Imaging 2018;11(4):561-572.

8- Leyva F, Zegard A, Acquaye E, Gubran C, Taylor R, Foley PWX, Umar F, Patel K, Panting J, Marshall H, Qiu T. Outcomes of Cardiac Resynchronization Therapy With or Without Defibrillation in Patients With Nonischemic Cardiomyopathy. J Am Coll Cardiol 2017;70(10):1216-1227.

9- Liddy S, Buckley U, Kok HK, Loo B, Glover B, Dhillon GR, Buckley O. Applications of cardiac computed tomography in electrophysiology intervention. Eur Heart J Cardiovasc Imaging 2018;19(3):253-261.

10- Truong QA, Szymonifka J, Picard MH, Thai WE, Wai B, Cheung JW, Heist EK, Hoffmann U, Singh JP. Utility of dual-source computed-tomography in cardiac resynchronization therapy-DIRECT study. Heart Rhythm 2018;15(8):1206-1213.

11- Ustunkaya T, Desjardins B, Liu B, Zahid S, Park J, Saju N, Trayanova N, Zimmerman SL, Marchlinski FE, Nazarian S.. Association of regional myocardial conduction velocity with the distribution of hypoattenuation on contrast-enhanced perfusion computed tomography in patients with post-infarct ventricular tachycardia. Heart Rhythm 2019 (4):588-594

12- Margulescu AD, Nuñez-Garcia M, Alarcón F, Benito EM, Enomoto N, Cozzari J, Chipa F, Fernandez H, Borras R, Guasch E, Butakoff C, Tolosana JM, Arbelo E, Camara O, Mont L. Reproducibility and accuracy of late gadolinium enhancement 
cardiac magnetic resonance measurements for the detection of left atrial fibrosis in patients undergoing atrial fibrillation ablation procedures. Europace 2019 21(5):724731

13- Bax JJ, Delgado V. Detection of viable myocardium and scar tissue. Eur Heart J Cardiovasc Imaging 2015 (10):1062-1064

14- Amara N, Boveda S, Defaye P, Klug D, Treguer F, Amet D, Perier MC, Gras D, Algalarrondo V, Bouzeman A, Piot $\quad$ O, Deharo JC, Fauchier L, Babuty D, Bordachar P, Sadoul N, Marijon E, Leclercq C; DAI-PP Investigators. Implantable cardioverter-defibrillator therapy among patients with non-ischaemic vs. ischaemic cardiomyopathy for primary prevention of sudden cardiac death. Europace 2018;20(1):65-72.

15- Kutyifa V, Moss AJ, Solomon SD, McNitt S, Aktas MK, Barsheshet A, Merkely B, Zareba W, Goldenberg I. Reduced risk of life-threatening ventricular tachyarrhythmias with cardiac resynchronization therapy: relationship to left ventricular ejection fraction. Eur J Heart Fail 2015;17(9):971-978.

16-García-Lunar I, Castro-Urda V, Toquero-Ramos J, Mingo-Santos S, MoñivasPalomero V, Daniela Mitroi C, Sánchez-García M, Pérez-Pereira E, Delgado HE, Fernández-Lozano I Ventricular arrhythmias in super-responders to cardiac resynchronization therapy. Rev Esp Cardiol (Engl Ed) 2014;67(11):883-889

17- Acosta J, Fernández-Armenta J, Borràs R, Anguera I, Bisbal F, Martí-Almor J, Tolosana JM, Penela D, Andreu D, Soto-Iglesias D, Evertz R, Matiello M, Alonso C, Villuendas R, de Caralt TM, Perea RJ, Ortiz JT, Bosch X, Serra L, Planes X, Greiser A, Ekinci O, Lasalvia L, Mont L, Berruezo A. Scar Characterization to Predict Life-Threatening Arrhythmic Events and Sudden Cardiac Death in Patients 
With Cardiac Resynchronization Therapy: The GAUDI-CRT Study. JACC Cardiovasc Imaging 2018;11(4):561-572.

18- Biton Y, Goldenberg I, Kutyifa V, Baman JR, Solomon S, Moss AJ, Szepietowska B, McNitt S, Polonsky B, Zareba W, Barsheshet A. Relative Wall Thickness and the Risk for Ventricular Tachyarrhythmias in Patients With Left Ventricular Dysfunction. J Am Coll Cardiol 2016;67(3):303-312

19-Zeppenfeld K. Ventricular Tachycardia Ablation in Nonischemic Cardiomyopathy. JACC Clin Electrophysiol 2018;4(9):1123-1140.

20- Piers SR, Everaerts K, van der Geest RJ, Hazebroek MR, Siebelink HM, Pison LA, Schalij MJ, Bekkers SC, Heymans S, Zeppenfeld K. Myocardial scar predicts monomorphic ventricular tachycardia but not polymorphic ventricular tachycardia or ventricular fibrillation in nonischemic dilated cardiomyopathy. Heart Rhythm $2015 ; 12: 2106-2114$. 


\section{FIGURE LEGENDS}

FIGURE 1: Location of segments with WT<6mm between NICM patients with or without VA episodes. LV=Left ventricle; VA=Ventricular arrhythmia

FIGURE 2: 2-years survival free from ventricular arrhythmia by the total percentage of LV WT $<6 \mathbf{6 m m}$. LV=Left ventricle; WT=Wall thickness

FIGURE 3: Example of patients with or without $\geq 40 \%$ of total $L V$ WT $<6 \mathrm{~mm}$ and with and without occurrence of VA. White arrow=basal segments with reduced WT. LV=Left ventricle; $\mathrm{VA}=$ Ventricular arrhythmia; WT=Wall thickness. 
Patients with VA

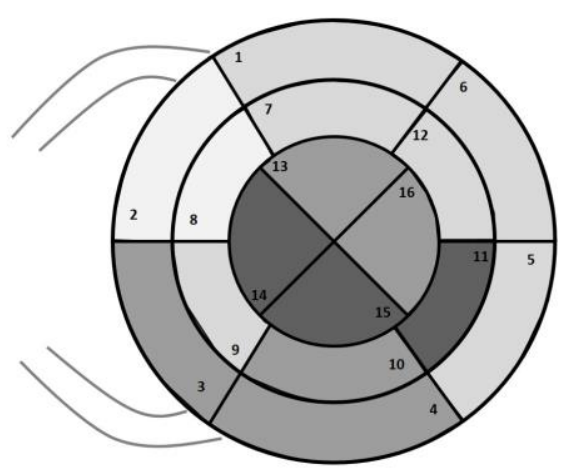

Patients without VA

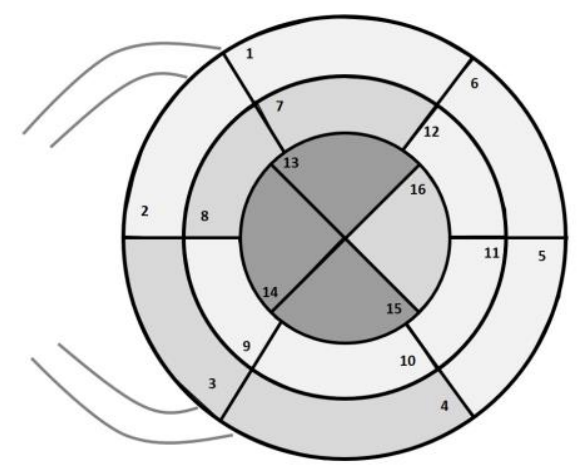




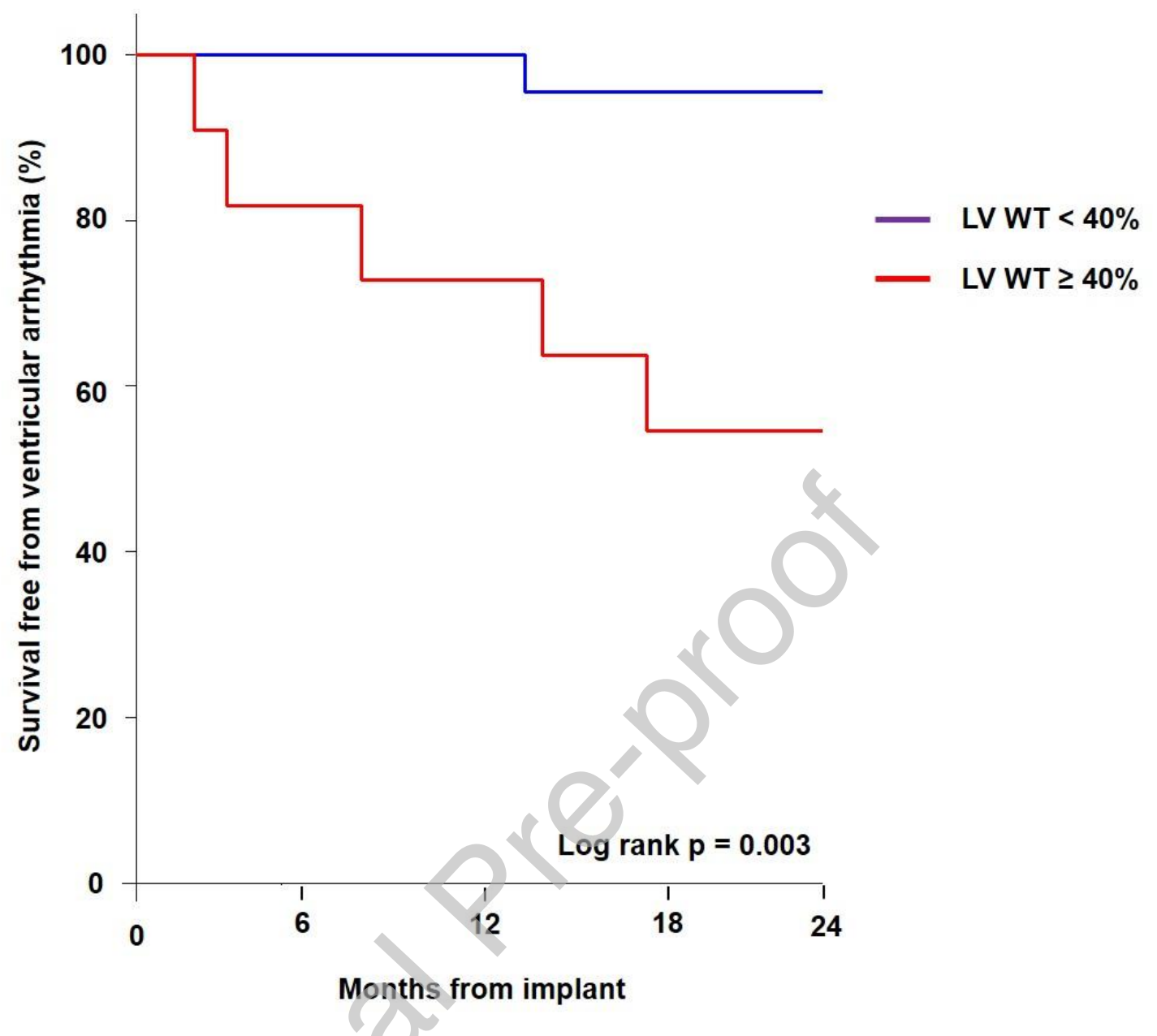




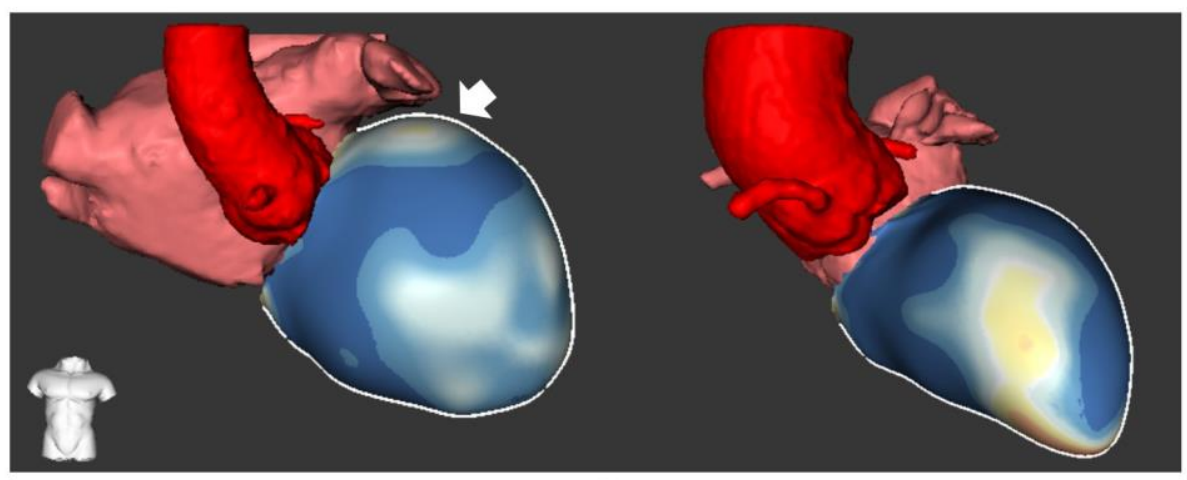

WT Threshold
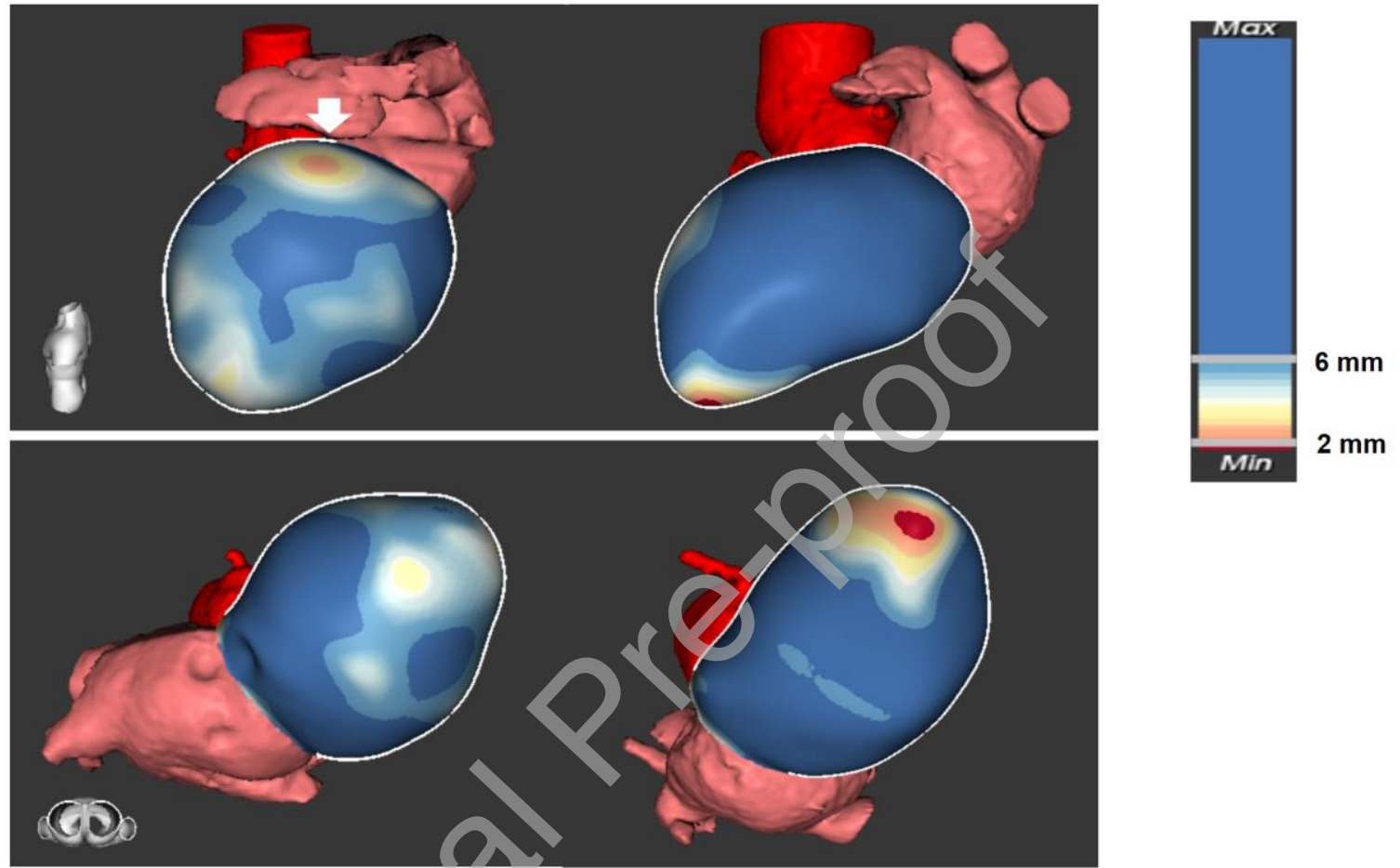

Total area with LV WT $<6 \mathrm{~mm}=\underline{55 \%}$<smiles>C1CCCC1</smiles>

PATIENT WITH VA EPISODE
Total area with LV WT $<6 \mathrm{~mm}=\underline{\mathbf{2 5} \%}$<smiles>C1CC2CCC2C1</smiles>

PATIENT WITHOUT VA EPISODE 


\begin{tabular}{|c|c|c|c|}
\hline \multirow[b]{2}{*}{ Variable } & \multicolumn{2}{|c|}{ Ventricular arrhythmia } & \multirow[b]{2}{*}{ p Value } \\
\hline & $\begin{array}{c}\text { Yes } \\
(n=6)\end{array}$ & $\begin{array}{c}\text { No } \\
(\mathrm{n}=27)\end{array}$ & \\
\hline Age (years) & $56.0(54.0-59.0)$ & $58.0(51.2-69.5)$ & 0.694 \\
\hline Body mass index, kg/m² & $29.9 \pm 3.0$ & $28.6 \pm 5.2$ & 0.552 \\
\hline Men & $5(83 \%)$ & $16(53 \%)$ & 0.379 \\
\hline Hypertension & $2(33 \%)$ & $12(44 \%)$ & 0.967 \\
\hline Diabetes mellitus & $2(33 \%)$ & $4(15 \%)$ & 0.632 \\
\hline $\begin{array}{l}\text { NYHA functional status } \\
\text {-II } \\
\text {-III }\end{array}$ & $\begin{array}{c}0(0 \%) \\
6(100 \%)\end{array}$ & $\begin{array}{l}8(31 \%) \\
19(69 \%)\end{array}$ & 0.296 \\
\hline Left bundle branch block & $3(50 \%)$ & $22(81 \%)$ & 0.271 \\
\hline $\begin{array}{l}\text { Baseline medication } \\
\text {-Beta blockers } \\
\text {-Angiotensin-converting enzyme inhibitor / }\end{array}$ & $\begin{array}{l}5(83 \%) \\
6(100 \%)\end{array}$ & $\begin{array}{l}25(93 \%) \\
20(74 \%)\end{array}$ & $\begin{array}{l}0.464 \\
0.301\end{array}$ \\
\hline $\begin{array}{l}\text { Angiotensin II receptor blocker } \\
\text {-Spironolactone } \\
\text {-Diuretics } \\
\text {-Anti-arrhythmic drugs }\end{array}$ & $\begin{array}{l}3(50 \%) \\
4(67 \%) \\
1(17 \%)\end{array}$ & $\begin{array}{l}11(41 \%) \\
16(59 \%) \\
3(11 \%) \\
\end{array}$ & $\begin{array}{l}0.967 \\
0.900 \\
0.753\end{array}$ \\
\hline $\begin{array}{l}\text { Laboratory parameters } \\
\text {-Creatinine, mg/dL } \\
\text {-NT-proBNP, pg/mL }\end{array}$ & $\begin{array}{c}1.11(0.94-1.27) \\
2499.5 \pm 1213.7\end{array}$ & $\begin{array}{c}0.96(0.88-1.04) \\
1104.5 \pm 1213.7\end{array}$ & $\begin{array}{l}0.252 \\
\mathbf{0 . 0 2 9}\end{array}$ \\
\hline Left ventricular ejection fraction $(\%)$ & $22.7 \pm 7.8$ & $26.6 \pm 8.2$ & 0.298 \\
\hline $\begin{array}{l}\text { Left ventricular end-diastolic diameter } \\
(\mathrm{mm})\end{array}$ & $68.2 \pm 13.1$ & $64.9 \pm 13.5$ & 0.593 \\
\hline Left ventricular end-diastolic volume $(\mathrm{ml})$ & $270.7 \pm 94.5$ & $231.0 \pm 110.9$ & 0.424 \\
\hline Left ventricular end-systolic volume $(\mathrm{ml})$ & $211.8 \pm 95.6$ & $166.2 \pm 96.5$ & 0.303 \\
\hline Left atrial diameter $(\overline{\mathrm{mm}})$ & $45.8 \pm 4.4$ & $42.6 \pm 6.7$ & 0.274 \\
\hline Interventricular septum thickness (mm) & $10.0 \pm 2.8$ & $9.7 \pm 2.0$ & 0.729 \\
\hline Posterior wall thickness (mm) & $10.8 \pm 1.3$ & $10.1 \pm 1.9$ & 0.362 \\
\hline $\begin{array}{l}\text { Mitral regurgitation } \\
\text {-I } \\
\text {-II } \\
\text {-III } \\
\text {-IV }\end{array}$ & $\begin{array}{l}1(17 \%) \\
2(33 \%) \\
3(50 \%) \\
0(0 \%)\end{array}$ & $\begin{array}{l}7(26 \%) \\
10(37 \%) \\
6(22 \%) \\
4(15 \%)\end{array}$ & 0.555 \\
\hline Total left ventricular area $\left(\mathrm{cm}^{2}\right)$ & $215.8 \pm 63.7$ & $172.9 \pm 59.4$ & 0.124 \\
\hline Left ventricular area with $\mathrm{WT}<6 \mathrm{~mm}\left(\mathrm{~cm}^{2}\right)$ & $118.0(72.3-157.2)$ & $31.8(19.6-66.9)$ & 0.018 \\
\hline Left ventricular area with $\mathrm{WT}<6 \mathrm{~mm}(\%)$ & $49.5 \pm 16.7$ & $25.8 \pm 17.6$ & 0.005 \\
\hline $\begin{array}{l}\text { Number of left ventricular segments with } \\
\text { WT }<6 \mathrm{~mm}\end{array}$ & $9.0(8.0-10.0)$ & $3.5(2.0-8.0)$ & 0.016 \\
\hline Number of basal segments with WT $<6 \mathrm{~mm}$ & $2.0(2.0-3.0)$ & $0.0(0.0-2.0)$ & 0.008 \\
\hline Number of mid segments with WT $<6 \mathrm{~mm}$ & $3.0(2.0-3.0)$ & $1.0(0.0-2.75)$ & 19.052 \\
\hline Number of apical segments with $\mathrm{WT}<6 \mathrm{~mm}$ & $4.0(2.0-4.0)$ & $3.0(2.0-3.0)$ & 0.149 \\
\hline
\end{tabular}




\begin{tabular}{|lccc|}
\hline Left ventricular lead location & & & \\
-Non-apical location & $5(83 \%)$ & $24(89 \%)$ & 0.753 \\
-Postero-lateral location & $6(100 \%)$ & $22(81 \%)$ & 0.607 \\
\hline Right ventricular lead location & & & 0.563 \\
-Apical location & $6(100 \%)$ & $21(78 \%)$ & \\
-Septal location & $0(0 \%)$ & $6(22 \%)$ & \\
\hline Biventricular pacing at 6 months (\%) & $99.0(97.5-99.0)$ & $99.0(98.0-99.0)$ & 0.875 \\
\hline
\end{tabular}

Table 1. Baseline characteristics between patients with or without occurrence of ventricular arrhythmia. 